\title{
Construção de uma lente líquida de foco ajustável para o ensino de óptica
}

\author{
Melo Neto, J. D. ${ }^{1,2^{*}}$; Dias, N.L. ${ }^{3}$; Abagaro, B. T. O. ${ }^{1,4}$ \\ 1 Mestrado Nacional Profissional em Ensino de Física - Polo 23, Universidade Estadual do Ceará, Quixadá, CE, Brasil \\ 2 Instituto de Ciências Exatas e da Natureza, Universidade da Integração Internacional da Lusofonia Afro-Brasileira, \\ Redenção, CE, Brasil. \\ 3 Departamento de Física, Universidade Federal do Ceará, Fortaleza, CE, Brasil. \\ 4 Faculdade de Filosofia Dom Aureliana Matos, Universidade Estadual do Ceará, Limoeiro do Norte, CE, Brasil. \\ *e-mail: joaodionizio@unilab.edu.br
}

\begin{abstract}
Resumo
Apresentamos uma proposta de construção de uma lente líquida de foco ajustável de baixo custo para o ensino de óptica, fácil de ser replicada e com diversas vantagens em comparação com as lentes tradicionais de foco fixo. A lente desenvolvida é prática e simples de manusear. $O$ seu uso permite trabalhar diversos fenômenos abordados no livros didáticos de física como, por exemplo, o comportamento dos raios, formação de imagens, verificação do foco da lente. Outro aspecto é que essa lente permite explorar o ensino em um contexto tecnológico dado o uso de lentes de foco ajustável em diversos sistemas ópticos.
\end{abstract}

\begin{abstract}
We present a proposal to build a low-cost adjustable focus liquid lens for optics teaching, easy to replicate and with several advantages compared to traditional fixed focus lenses. The developed lens is practical and simple to handle. Besides, its use allows to work several phenomena covered in physics textbooks, for example, the ray behaviour, image formation, determination of the vergence of the lens. Another aspect is that this lens allows to explore teaching in a technological context given the use of adjustable focus lenses in various optical systems.
\end{abstract}

Keywords: Liquid Lenses, Optics teaching, Variable focus.

\section{Introdução}

No contexto da Óptica, lentes são dispositivos que possuem superfícies refratoras por onde ocorre 0 desvio da luz. Caracterizam-se por serem um dos aparatos ópticos mais utilizados em nossa tecnologia e o seu estudo consiste em um tópico central no ensino da óptica geométrica. Podemos construir lentes com diversos materiais, por exemplo, um líquido dentro de um recipiente transparente produz um comportamento de uma lente, nesse caso chamamos de lente líquida. Quando as superfícies de uma lente líquida podem ser deformadas de uma forma controlada, podemos então alterar e ajustar a sua distância focal. Entre os diversos tipos de mecanismos de funcionamento de uma lente líquida de foco ajustável, destacam-se as lentes líquidas cuja curvatura da sua superfície pode ser modificada pela aplicação de uma diferença de potencial por meio do efeito de "electrowetting" [1] permitindo através dessa tecnologia construir lentes de dimensões reduzidas que podem ser usadas em dispositivos móveis [2]. Outro tipo de lente líquida de foco variável é aquela cuja curvatura da sua superfície pode ser alterada pela injeção ou retirada de líquido de dentro de uma câmara por meio de bombeamento [3], lentes que possuem esse mecanismo de bombeamento foram utilizadas para a construção de óculos de baixo custo em países em desenvolvimento [4]. No contexto do ensino experimental de Óptica, há a construção de uma lente líquida para servir de modelo do cristalino do olho humano, que consiste em uma placa de Petri e na 
extremidade aberta um filme elástico esticado [5]. A PASCO Optics possui em seu catálogo lente líquida, que consiste em uma seringa de $10 \mathrm{~mL}$ para 0 bombeamento, e tubo de plástico (câmera de armazenamento) com membranas flexíveis nas laterais [6]. É uma tradição no ensino da Óptica Geométrica dar ênfase nos aspectos geométricos e fórmulas envolvendo o tópico de lentes muitas vezes, distante de um ensino mais abrangente e contextualizado com os fenômenos ópticos e o cotidiano do estudante. Porém, para um efetivo ensino de Física é necessário que o estudante desenvolva a capacidade de reconhecer os fenômenos que estão no seu cotidiano. Além disso, construir conhecimentos com as suas próprias experiências e usar nas situações diárias ao longo de sua vida, numa abordagem integradora a realidade dos estudantes, e não de maneira desconexa e sem sentido [7]. Pensando em apresentar uma proposta mais rica de possibilidades no ensino de lentes do que o que geralmente é apresentado no ensino que usa as lentes tradicionais, descrevemos, a seguir, a construção e exemplificamos com algumas aplicações de uma lente líquida de foco ajustável no ensino de Óptica.

\section{Materiais e Métodos}

\subsection{Materiais}

As lentes líquidas mecânicas são basicamente formadas por uma câmara na qual se armazena o líquido, as membranas flexíveis como superfícies da lente, e um canal por onde é conduzido o bombeamento do líquido [8]. Para as lentes desenvolvidas neste trabalho, foram usados materiais de fácil aquisição, de forma a viabilizar a aplicação em sala de aula. Dessa forma, os materiais são: Uma seringa de $20 \mathrm{~mL}$; um pedaço de cano de PVC de 25 mm (diâmetro externo); um equipo de soro; um preservativo masculino (denominaremos de membrana de látex), que será cortado para ser usado como membrana flexível e uma lixa para madeira número 180.

\subsection{Procedimentos da construção}

Primeiramente, para a construção da câmara, um pedaço de cano de PVC foi cortado (cerca de 12,40 $\mathrm{mm}$ de espessura). Depois foram lixadas as laterais para evitar danos às membranas de látex no momento da fixação nas bordas do cano cortado. Em seguida, foi feito um furo com uma broca de $3 \mathrm{~mm}$, por onde é fixado a cânula, conforme Figura 1.

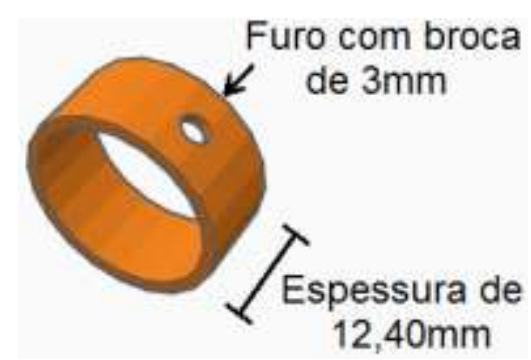

Figura 1: Estrutura da câmara de PVC (25mm de diâmetro) com espessura de $12,40 \mathrm{~mm}$ e adaptações realizadas (furo de $4 \mathrm{~mm}$ ).

O equipo de soro tem uma cânula na qual se retira $15 \mathrm{~cm}$, que serve de canal para a passagem do líquido da lente. A cânula é conectada ao cano de PVC através do furo feito, esse acoplamento deve ser cingido, de forma que a cânula penetre com vedação adequada, evitando futuros vazamentos do líquido. Para segurar as membranas flexíveis nas laterais da câmara de PVC, foram utilizados anéis de vedação ou presilhas de vedação (figura 2), que servem para firmar as superfícies da lente. Esses anéis de vedação foram confeccionados com mesmo cano de PVC de $25 \mathrm{~mm}$, para a fixação das membranas de látex nas laterais da câmara, o diâmetro das presilhas de vedação deve ser maior que o diâmetro externo da câmara. Para isso, dilata-se o cano em chama, processo usual em conexões caseiras entre dois canos de mesmo diâmetro, corta-se esse cano em forma de anéis, o mais fino possível, espessuras em torno de $2 \mathrm{~mm}$, e lixa-se esses anéis, pois evitará de rasgar a membrana flexível no momento do encaixe dos anéis de vedação.

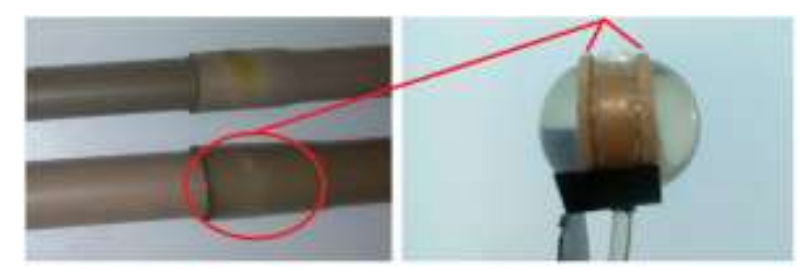

Figura 2: Anéis de vedação ou presilhas de vedação, também feitas de $\operatorname{PVC}(\simeq 2 \mathrm{~mm})$. 
Foram recortadas cuidadosamente duas membranas de látex em um formato circular, um pouco maior que o diâmetro externo da câmara e fixadas pelos anéis de vedação. Em seguida, retira-se o êmbolo da seringa, e conecta-se a cânula, para então preencher com água, de maneira que não fique nenhuma bolha de ar dentro do sistema câmara-cânula-seringa, Figura 3.

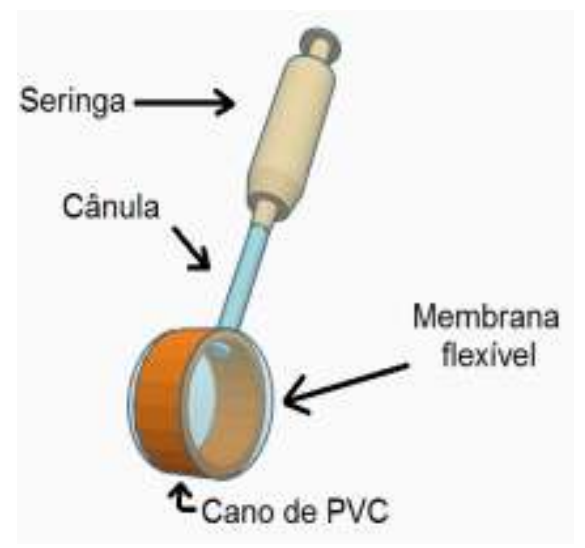

Figura 3: Esquema completo da lente líquida de foco ajustável.

Antes de colocar o êmbolo da seringa é importante fazer uma pressão lateral nas membranas com os dedos, até as faces se tocarem. O diâmetro externo do cano de PVC escolhido foi o de $25 \mathrm{~mm}$ porque ao se utilizar em nossos testes tal dimensão, não ocorreu um grande desvio de curvatura que é encontrado em diâmetros maiores, devido ao efeito de deformação pela ação da gravidade [9]. Diâmetros menores não são convenientes, pois podem dificultar a observação das imagens e da visualização de raios pelos estudantes. Observou-se que a durabilidade da membrana de látex foi em torno de dois meses. Para apoiar melhor a lente líquida de foco ajustável, construiu-se um suporte com alumínio maleável, Figura 4.

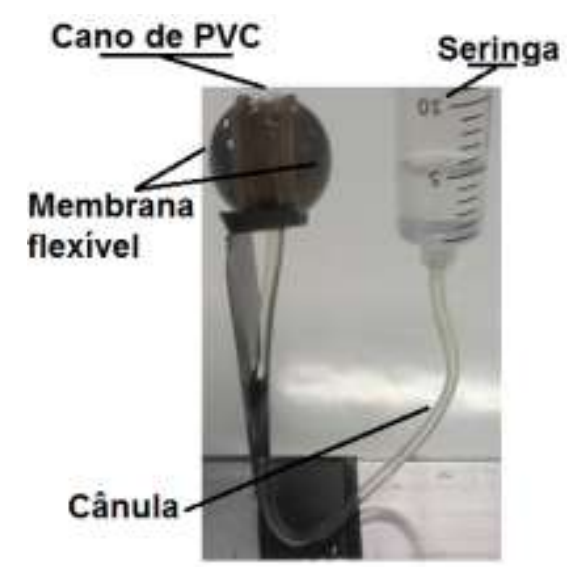

Figura 4: Lente líquida de foco ajustável com um suporte de alumínio.

Ao se injetar o líquido, a membrana flexível de látex se deforma assumindo uma curvatura de lente biconvexa, com comportamento de lente convergente. $\mathrm{E}$ ao se retirar o líquido, puxando o êmbolo da seringa, a lente se tornará bicôncava, com atuação de lente divergente.

\section{Resultados e Discussão}

A lente líquida de foco ajustável proposta neste trabalho foi montada com materiais de fácil aquisição, e de baixo custo. Outro aspecto de destaque é que a sua construção é simples e pode ser realizada rapidamente, otimizando o tempo do professor. Esta lente proporciona tanto ao professor, como ao aluno, a oportunidade de investigar vários fenômenos ópticos previstos nos livros didáticos do ensino fundamental e médio, com a lente construída, há inúmeras possibilidades de trabalhar no ensino de óptica. $O$ conjunto de assuntos a serem estudados com essa lente são diversos:

\subsection{Nomenclatura das lentes}

As lentes esféricas, quanto a sua nomenclatura, podem ser: Plano-Côncava, Bicôncava, Côncavo-convexa, Plano-Convexa, Biconvexa ou Convexa-côncava. Com a lente desenvolvida é possível formar a bicôncava e a biconvexa. 

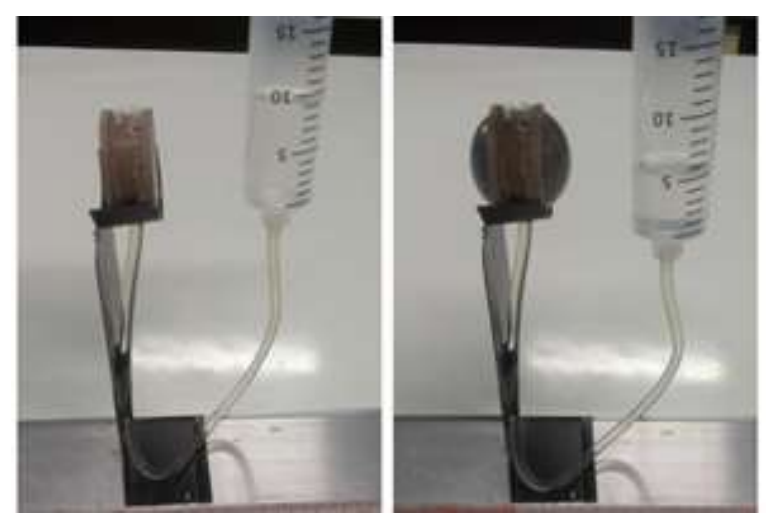

Figura 5: Na esquerda temos uma bicôncava, retirando o líquido as superfícies estão côncavas. Na foto à direita temos uma biconvexa, ao injetar o líquido as superfícies ficam acentuadas.

\subsection{Caracterização de imagens}

As imagens podem ser: direita ou invertida e menor, maior ou igual. Na figura 6 observa-se na esquerda uma folha de papel com as palavras UNILAB, UFC e UECE. Ao centro da figura 6 , a imagem é menor e direita formada pela lente líquida em seu formato bicôncava. E a direita da figura 6, a mesma lente líquida está no formato biconvexa, formando uma imagem maior e invertida.
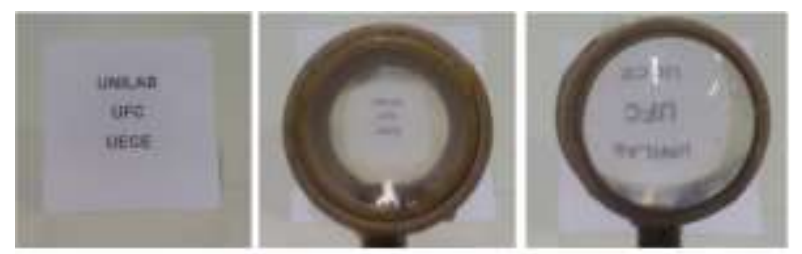

Figura 6: Formação de imagens com a lente líquida de foco ajustável. A esquerda palavras em um papel, no centro imagem da lente bicôncava, e a direita a imagem da lente biconvexa.

Na forma biconvexa, ainda é possível estudar as outras formas de imagens previstas para esse tipo de lente.

\subsection{Estudo do comportamento de raios paralelos ao passar pela lente}

Os raios podem convergir ou divergir ao passar por uma lente. Na figura 7(a), os raios chegam paralelos a lente, e a medida em que a lente assume o formato biconvexa, os raios vão convergindo. De maneira contrária, ocorre na figura 7(b), quando a lente apresenta a forma bicôncava, seus raios divergem. (a)
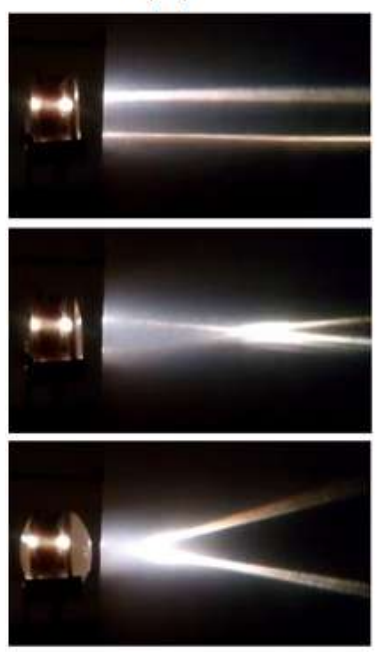

Figura 7: Na esquerda, 7(a), ajustando a lente líquida para o formato biconvexa, os raios convergem. Na direita, 7(b), ajustando a lente líquida para o formato bicôncava, os raios divergem.

\subsection{Aumento linear de uma lente convergente}

Projetando a imagem em um anteparo é possível estudar as relações de aumento linear. No lado esquerdo da figura 8 tem-se uma fonte de luz, que representa o objeto a ser projetado pela lente.
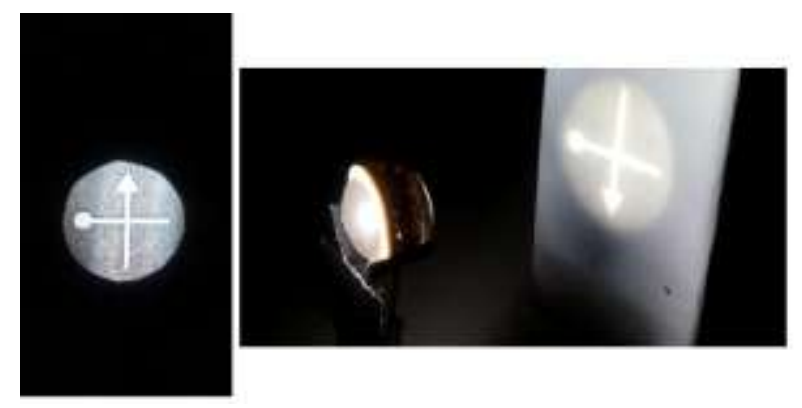

Figura 8: Na esquerda é a fonte de luz com dimensões iguais a da lente construída ( $25 \mathrm{~mm}$ ), à direita é a projeção da imagem pela lente em um anteparo.

Esse objeto (na parte esquerda da figura 8) tem a mesma circunferência da lente, ou seja, o tamanho da figura coincide com o tamanho da lente. No lado direito da figura 8 a lente é biconvexa, e projeta uma imagem invertida e maior no anteparo.

\subsection{Determinação da vergência da lente}

Com a ajuda do sol, é possível verificar a vergência da lente. Para isso, basta focalizar um ponto no chão com a lente e medir essa distância com uma régua. Deixando uma quantidade fixa de líquido na lente, ou 
seja, fixando o foco, é possível realizar a determinação da vergência da lente líquida, é o mesmo procedimento trabalhado com uma lente de foco fixo [10].

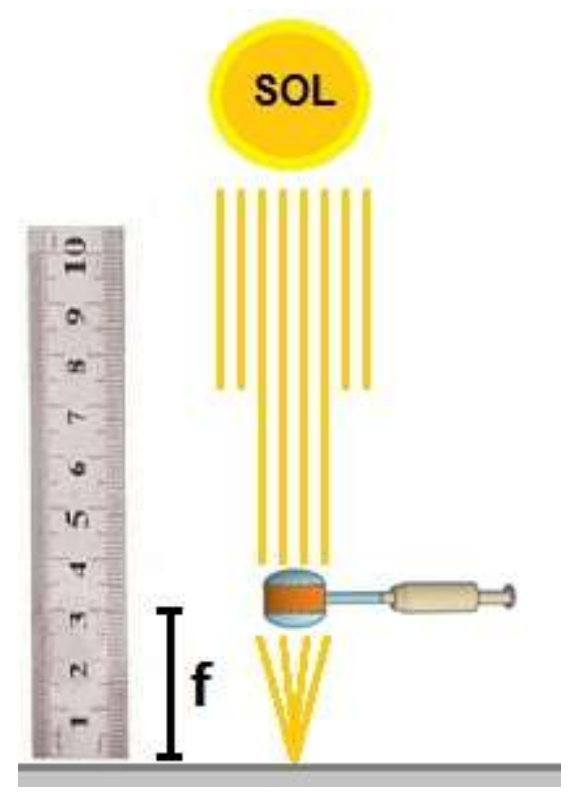

Figura 9: Determinando a vergência da lente, mantendo a quantidade de líquido fixo no interior da câmara de PVC.

Para essa determinação:

$$
V=\frac{1}{f}
$$

Onde $V$ é a vergência $\left(\mathrm{m}^{-1}\right)$, sendo $1 \mathrm{di}$ (dioptria) $=1 \mathrm{~m}^{-1}$, popularmente conhecida como grau da lente e f é a distância focal em metros $(m)$. Esses são alguns resultados da aplicação da lente líquida de foco ajustável para o ensino de óptica, há outras formas que podem ser exploradas, tais como montar instrumentos ópticos, ou mudar o líquido da lente, ao invés de água usar glicerina e estudar as relações do índice de refração, dentre outros mais.

\section{Considerações finais}

Apresentamos uma proposta de construção de uma lente líquida de foco ajustável de baixo custo para o ensino de óptica geométrica, fácil de ser replicada e com diversas vantagens em comparação com as lentes tradicionais de foco fixo. A lente desenvolvida é prática, simples de construir e de montar. É versátil, pois ao contrário das lentes de foco fixo, com uma única lente pode-se, dependendo do volume de líquido injetado ou retirado, mudar seu comportamento (convergente ou divergente) pela mudança do raio de curvatura. A lente também pode ter seu índice de refração facilmente alterado pela troca de substância que preenche a câmara da lente. Desvios de curvatura da membrana também podem ser explorados com mais facilidade do que a lente com curvatura fixa, permitindo explorar casos não ideais, como a observação de aberrações esféricas. Outro aspecto é que essa lente permite explorar o ensino contextualizado pois essa lente pode simular o comportamento do cristalino do olho humano [5] além de seu uso no ensino em um contexto tecnológico, dado o uso de lentes de foco ajustável em diversos sistemas ópticos, como em lentes de smartphones [2]. Dessa forma, as possibilidades de experimentação e investigação com o uso da lente líquida cuja construção e aplicação aqui apresentamos são mais amplas, dinâmicas e construtivas do que com a lente comum.

\section{Referências}

[1] Berge, B.; Peseux, J. Variable focus lens controlled by an external voltage: An application of electrowetting. Eur. Phys. J. E 3, 159-163, 2000.

[2] Kuiper, S.; Hendriks, B. H. W. Variable-focus liquid lens for miniature câmeras. Applied Physics Letters, vol. 85, n7, ago, 2004.

[3] N. Sugiura and S. Morita, "Variable-focus liquid-filled optical lens," Appl. Opt. 32, 4181-4186, 1993.

[4] Douali, M. G.; Silver, J. D. Self-optimised vision correction with adaptive spectacle lenses in developing countries. Ophthal. Physiol. Opt, 24, p 234-241, 2004.

[5] COLICCHIA, G.; Wiesner, H.; Waltner, C.; Zollman, D. A Model of the Human Eye. Physics Teacher, v46, n9, p528-531, Dez, 2008.

[6] PASCO, Optics. Manual de instruções: Adjustable Focal Length Lens. Disponível em: < https://www.pasco.com/file_downloads/Downloads_Ma nuals/Adjustable-Focal-Length-Lens-Manual-OS8494.pdf >. Acesso em: 01 mar. 2018. 
[7] CARvalho, A. M. P. (ORG.) et. Al. Ensino de Física. (Coleção ideias em ação/ Anna Maria Pessoa de Carvalho). p.5. São Paulo: Cengage Learning, 2010.

[8] C.-H. Wu, "Variable lens assembly," U.S. patent 5,233,470 13 Ago, 1993.

[9] N. Sugiura and S. Morita, "Variable-focus liquid-filled optical lens," Appl. Opt. 32, 4181-4186, 1993.

[10] VILAS BOAS, N.; DOCA, R. H.; BISCUOLA, G. J. Tópicos de Física. vol.2, p.431. São Paulo: Saraiva, 2012. 